\title{
Breast Cancer Status in Iran: Statistical Analysis of 3010 Cases between 1998 and 2014
}

\author{
Mohammad Esmaeil Akbari, ${ }^{1}$ Soheila Sayad, ${ }^{1,2}$ Saed Sayad, ${ }^{3}$ Maryam Khayamzadeh, ${ }^{1}$ \\ Leila Shojaee, ${ }^{1}$ Zeynab Shormeji, ${ }^{4}$ and Mojtaba Amiri ${ }^{5}$ \\ ${ }^{1}$ Cancer Research Center, Shahid Beheshti University of Medical Sciences, Tehran, Iran \\ ${ }^{2}$ Department of Surgery, Firoozgar Clinical Research Development Center, Iran University of Medical Sciences, Tehran, Iran \\ ${ }^{3}$ Department of Chemical Engineering and Applied Chemistry, Data Mining Research Group, University of Toronto, \\ Toronto, ON, Canada \\ ${ }^{4}$ Faculty of Management and Medical Information, Iran University of Medical Sciences, Tehran, Iran \\ ${ }^{5}$ Chemical Injuries Research Center, Baqiyatallah University of Medical Sciences, Tehran, Iran
}

Correspondence should be addressed to Soheila Sayad; sayad.soheila@yahoo.com

Received 20 June 2017; Revised 2 August 2017; Accepted 7 September 2017; Published 1 November 2017

Academic Editor: Peter A. Fasching

Copyright (C) 2017 Mohammad Esmaeil Akbari et al. This is an open access article distributed under the Creative Commons Attribution License, which permits unrestricted use, distribution, and reproduction in any medium, provided the original work is properly cited.

Background. Breast cancer is the 5th leading cause of cancer death in Iranian women. This study analyzed 3010 women with breast cancer that had been referred to a cancer research center in Tehran between 1998 and 2014. Methods. In this retrospective study, we analyzed 3010 breast cancer cases with 32 clinical and paraclinical attributes. We checked the data quality rigorously and removed any invalid values or records. The method was data mining (problem definition, data preparation, data exploration, modeling, evaluation, and deployment). However, only the descriptive analyses' results of the variables are presented in this article. To our knowledge, this is the most comprehensive study on breast cancer status in Iran. Results. A typical Iranian breast cancer patient has been a 40-50-year-old married woman with two children, who has a high school diploma and no history of abortion, smoking, or diabetes. Most patients were estrogen and progesterone receptor positive, human epidermal growth factor (HER) negative, and P53 negative. Most cases were detected in stage 2 with intermediate grade. Conclusion. This study revealed original findings which can be used in national policymaking to find the best early detection method and improve the care quality and breast cancer prevention in Iran.

\section{Background}

Breast cancer is the most common cancer in women worldwide, with nearly 1.7 million new cases diagnosed in 2012 (second most common cancer overall). This represents about $12 \%$ of all new cancer cases and $25 \%$ of all cancers in women $[1,2]$. Since many published works on breast cancer are from North America, Europe, and Japan, we tend to consider breast cancer primarily from their points of view. But this cancer is becoming a bigger challenge for developing countries.

In Iran, breast cancer is one of the most frequent malignancies in women. Its peak incidence age in Iranian women is in the fourth and fifth decades of life, which is a decade younger than the global peak age of incidence $[3,4]$. Because of Iran's socioeconomic status and the important role of women as mothers and the main caretakers of an extended family, breast cancer significantly damages the patient's family [5]. This makes planning and policymaking for early diagnosis of this disease and reducing its complications and mortality an important public health sector priority in Iran.

There have been a limited number of epidemiological studies on breast cancer in Iran, but none has been conducted on its early diagnosis [3]. Therefore, there has been an obvious and urgent need for an accurate statistical analysis of breast cancer in Iran not only to explore, understand, and explain this cancer more accurately but to develop a robust early diagnosis platform for public health professionals.

This study set out to analyze 3010 breast cancer cases (all women) that had referred to a Cancer Research Center in Tehran between 1998 and 2014. 


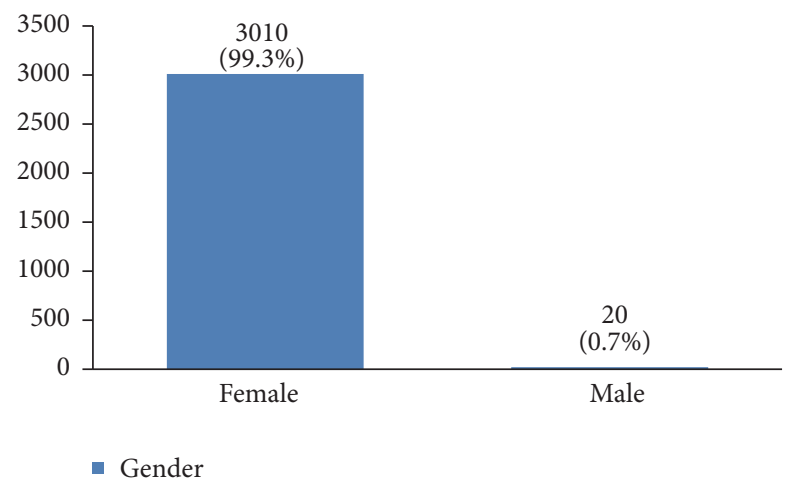

FIgURE 1: The sex distribution of the studied breast cancer patients.

\section{Materials and Methods}

This study's data were obtained from the Cancer Research Center of Shahid Beheshti University of Medical Sciences in Tehran. The Cancer Research Center's team has been collecting clinical, pathological, biological, and demographic information on breast cancer patients since 1998. The Cancer Research Center is a major referral center for breast cancer patients. It has cases from all provinces of Iran. It has the biggest data records of breast cancer cases in the country and can be representative of all Iran.

In total, we gathered, cleaned, and analyzed data from 3010 breast cancer patients. All clinical and paraclinical data have been obtained by two surgeons and recorded by a medical information specialist. The data quality has been checked rigorously and any invalid values or records have been excluded from the study. We saved the data in a relational database and followed and implemented data mining methodology (problem definition, data preparation, data exploration, modeling, model evaluation, and deployment) for long-term maintenance and accessibility for current and future statistical analysis and predictive modeling (e.g., score cards and survival analysis). We transferred our data to a SQL Server database and did all necessary quality checks. Then, we explored data using descriptive (univariate) and bivariate analysis using R. However, here we have presented the descriptive analyses' results of all 32 variables regarding breast cancer in Iran.

\section{Results}

A retrospective analysis was done on breast cancer patients diagnosed between 1998 and 2014 at the Cancer Research Center of Shahid Beheshti University of Medical Sciences in Tehran. Thus, the profiles of 3010 women with breast cancer were evaluated in this study. All the studied patients were followed up in the past 20 years. We excluded all men from our analyses (Figure 1). A total number of 32 variables were data mined and underwent descriptive analysis.

3.1. Demographics. The profiles of 3010 women with breast cancer were evaluated in this study. Their average age was $49.1 \pm 11.6$ years old. Most of them were between 40 and 50

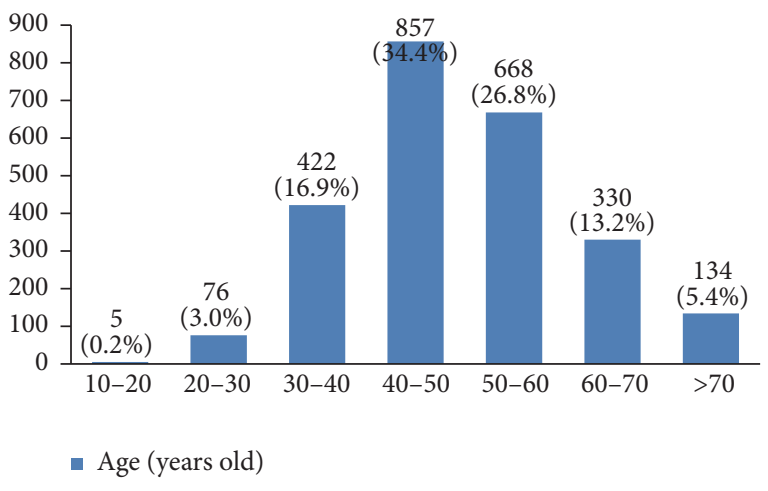

FIgURE 2: The age groups of the studied breast cancer cases.

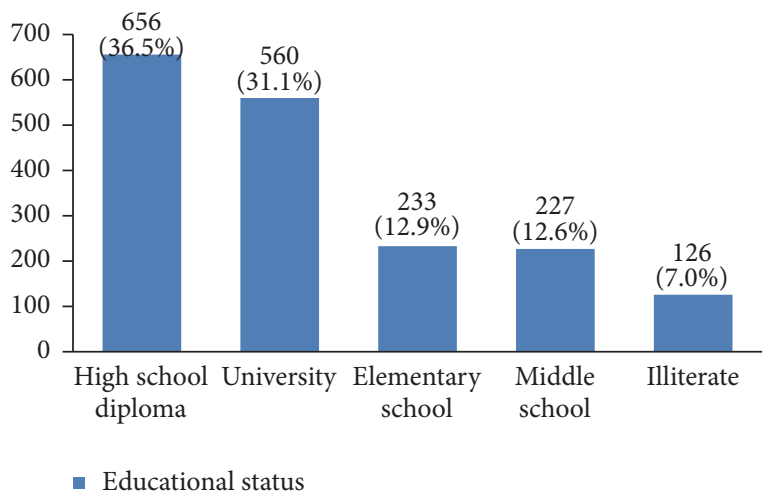

FIgURE 3: The educational status of the studied breast cancer cases.

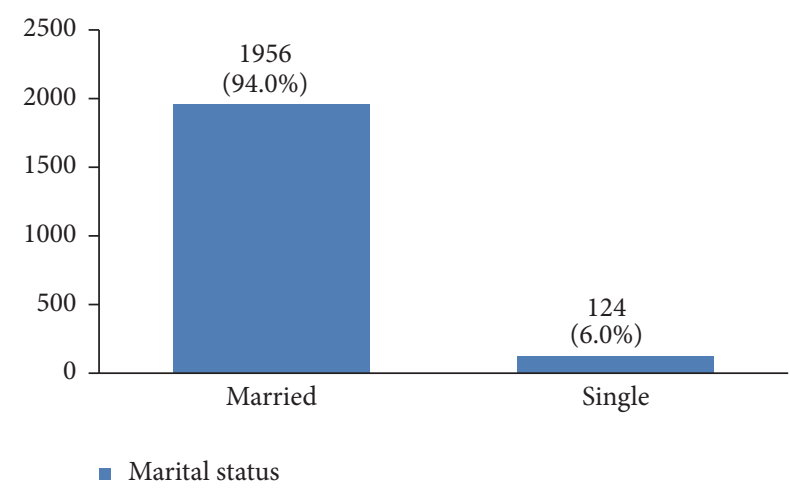

Figure 4: The marital status of the studied breast cancer cases.

years old (Figure 2). 36\% of them had a high school degree, $31 \%$ university degree, and 26\% elementary and middle school degree and only $7 \%$ were illiterate (Figure 3 ). $94 \%$ of the studied women were married (Figure 4).

3.2. Past History. In our study, most cases (72\%) reported 1 to 4 gravidity and $50 \%$ had 2 or less parity (Figures 5 and 6). Moreover, $11.5 \%$ of the patients had no pregnancies and $12.6 \%$ had no labor experience. $30 \%$ of the patients had one $(19 \%)$ or more abortions (11\%), mostly illegal (Figures 7 and 8). 12\% had no breastfeeding, 33\% breastfed for up to two years, and $27 \%$ breastfed for up to four years (Figure 9). Surprisingly, more than $80 \%$ of the studied women had reported no known 


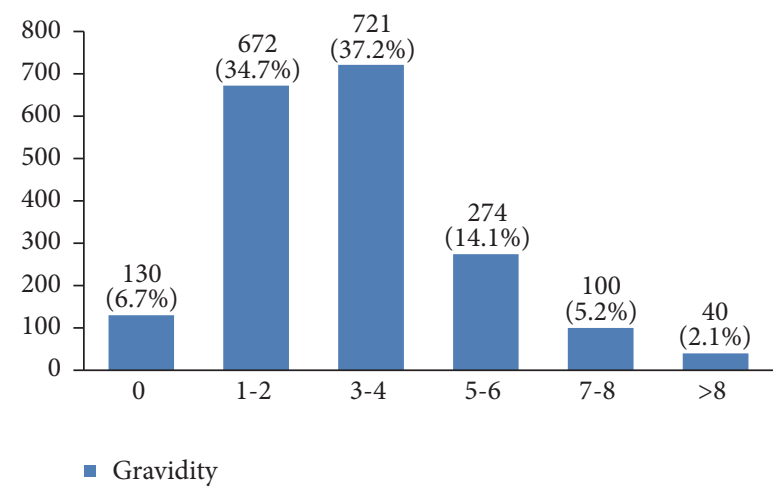

FIGURE 5: The gravidity of the studied breast cancer cases.

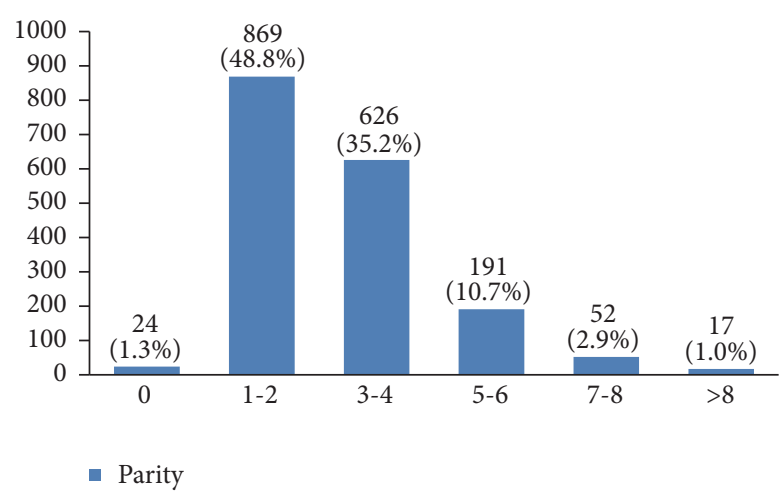

FIGURE 6: The parity of the studied breast cancer cases.

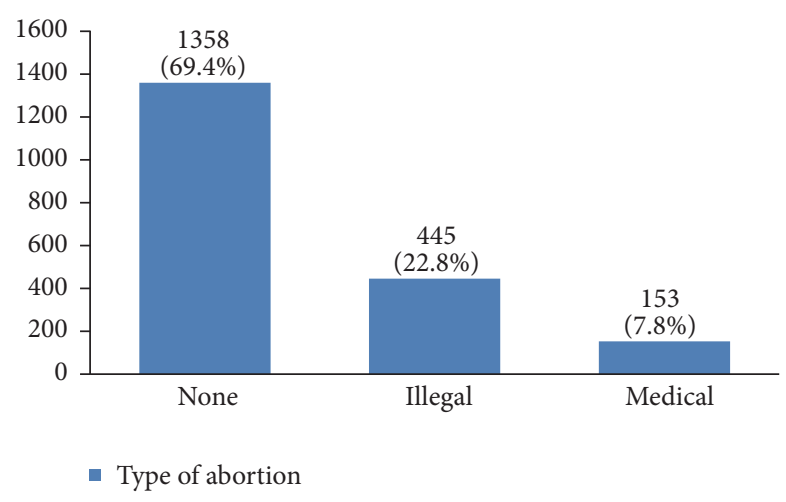

FIgURE 7: The abortion type of the studied breast cancer cases.

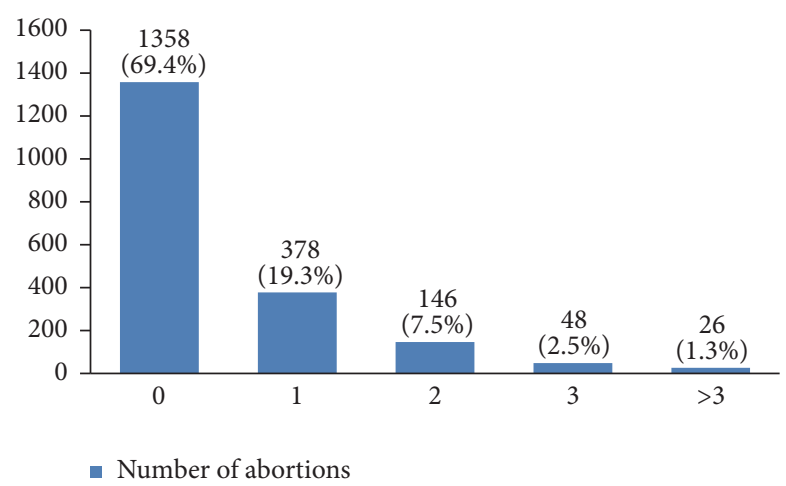

FIGURE 8: The number of abortions of the studied breast cancer cases.

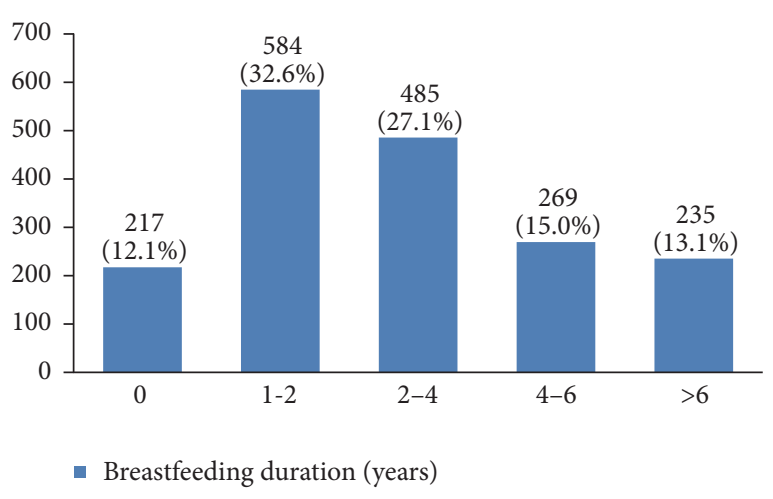

FIGURE 9: The breast feeding duration of the studied breast cancer cases.

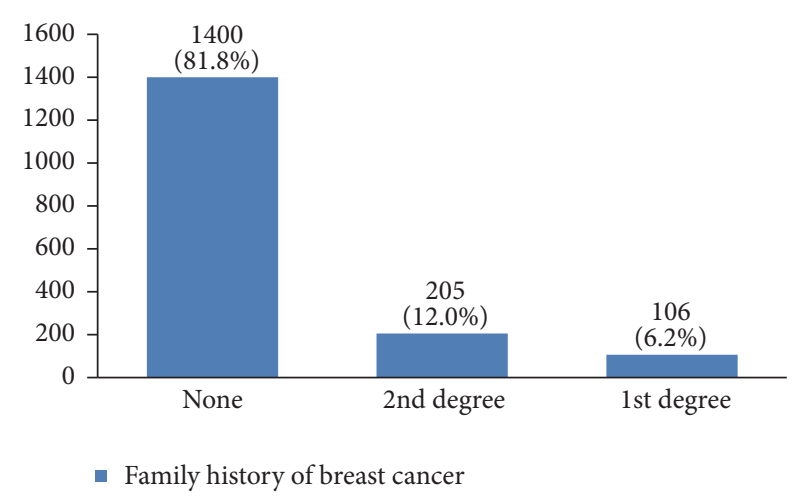

Figure 10: The family history of the studied breast cancer cases.

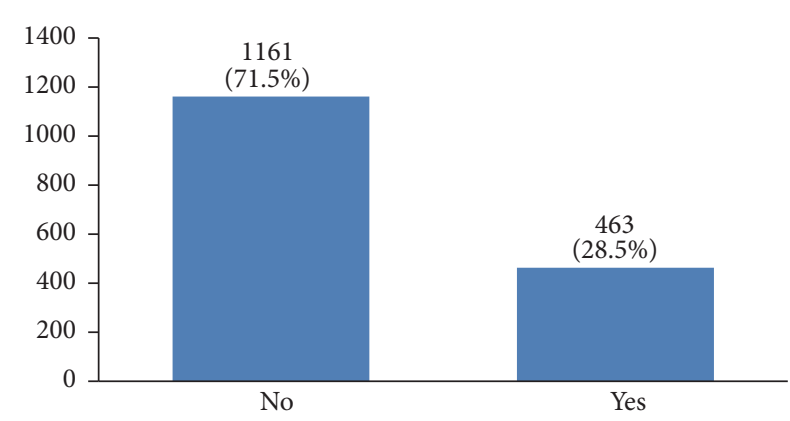

- Hormone consumption

FIGURE 11: The hormone consumption of the studied breast cancer cases.

family history of breast cancer (Figure 10). Only $28 \%$ of the patients had a history of using hormones (estrogen and progesterone) (Figure 11). $48 \%$ of the patients had a highfat regime (Figure 12), only 7\% were smokers (Figure 13), and $34 \%$ had diabetes (Figure 14). Two-thirds of the patients experienced menopause naturally and one-third had secondary menopause due to hysterectomy (Figure 15). Finally, $41 \%$ of the patients had undergone breast conserving surgery and 59\% had done modified radical mastectomy (Figure 16).

3.3. Histopathology. In almost $55 \%$ of the patients the tumor size was between 2 and 5 centimeters (Figure 17). In many 


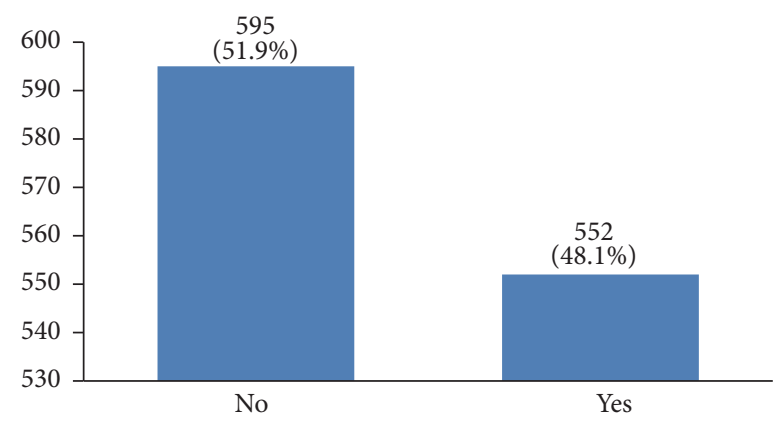

- Fatty food regimen

FIGURE 12: The fatty food regimen of the studied breast cancer cases.

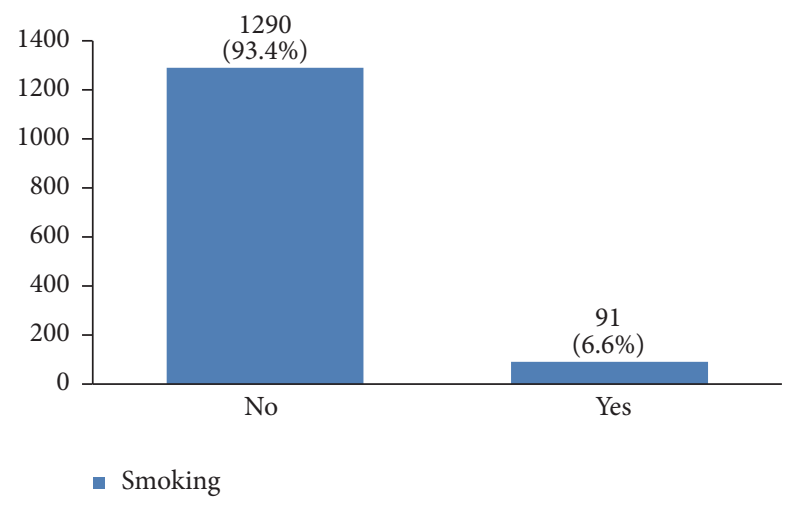

FIGURE 13: The smoking habit of the studied breast cancer cases.

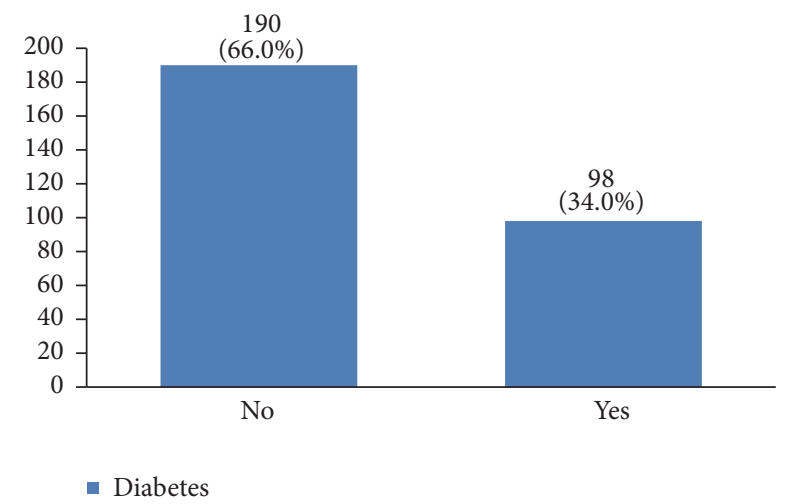

FIGURE 14: The diabetes status of the studied breast cancer cases.

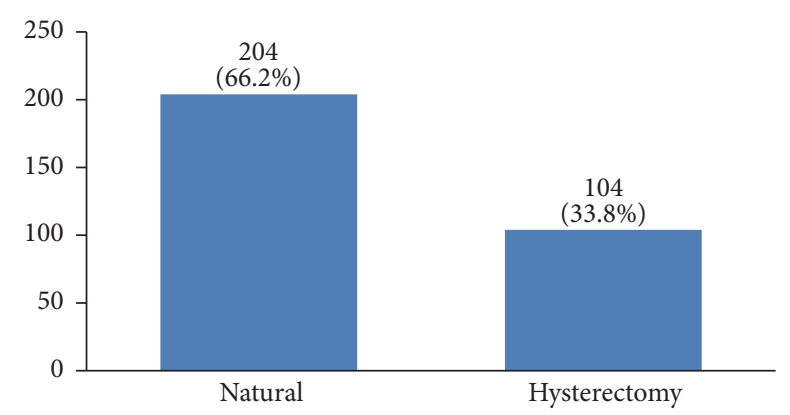

- Type of menopause

Figure 15: The menopause type of the studied breast cancer cases.

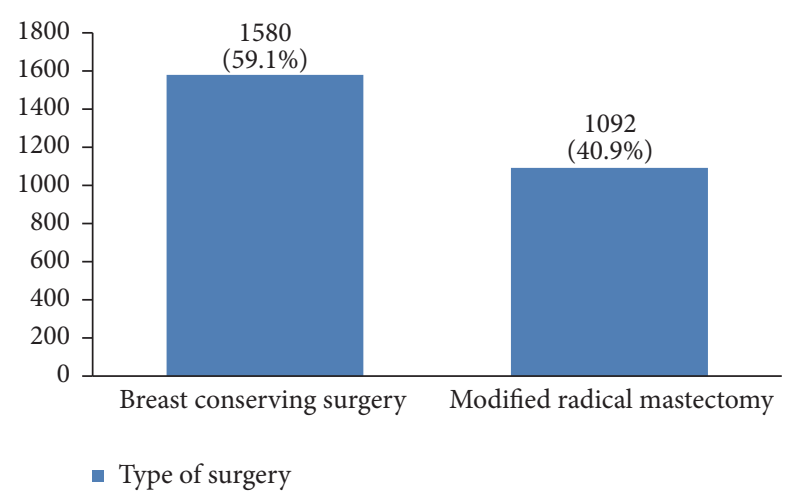

FIGURE 16: The surgery type of the studied breast cancer cases.

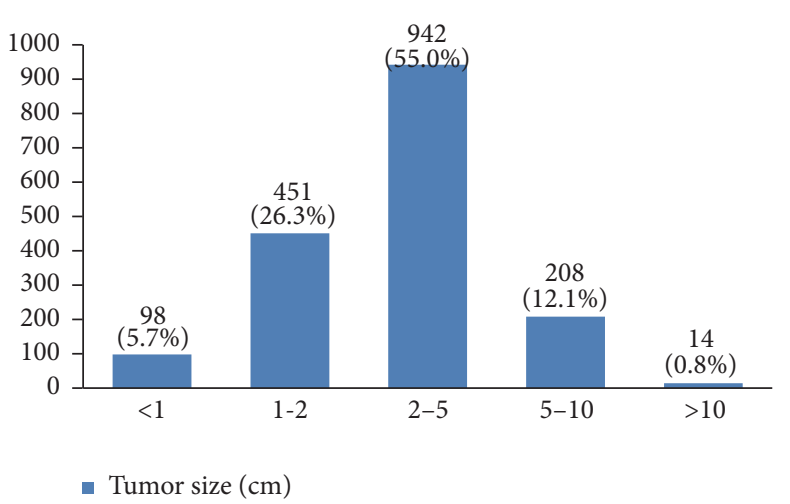

FIGURE 17: The tumor size of the studied breast cancer cases.

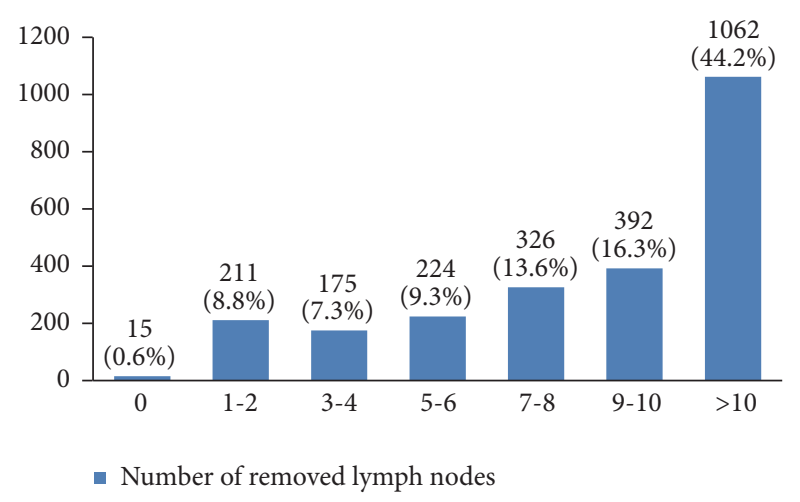

FIgURE 18: The number of removed lymph nodes in the studied cases.

patients (44\%) more than 10 lymph nodes had been removed (Figure 18). However, the highest rate of pathologically positive nodes (21\%) was between 1 and 2 (Figure 19). Regarding tumor stage, $20 \%$ of the studied women were in stage I, $46 \%$ in stage II, 30\% in stage III, and $4 \%$ in stage IV (Figure 20 ).

Regarding tumor grade, $54 \%$ were in intermittent grade, $34 \%$ in high grade, and $12 \%$ in low grade (Figure 21 ). Concerning pathology, $87 \%$ had invasive ductal carcinoma, $8 \%$ had invasive lobular carcinoma, and 5\% were in situ (Figure 22). Regarding the type of axillary surgery, 55\% had undergone axillary dissection, $38 \%$ sentinel node biopsy, and $7 \%$ sentinel node biopsy plus axillary dissection (Figure 23). 


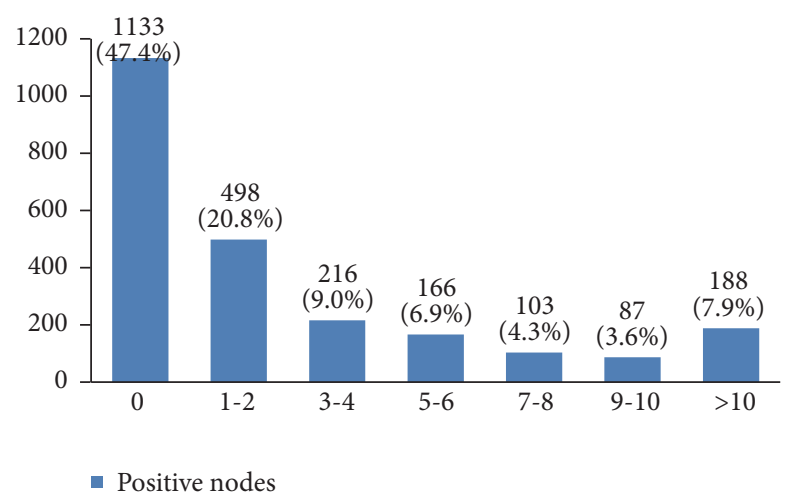

Figure 19: The number of pathologically positive nodes in the studied cases.

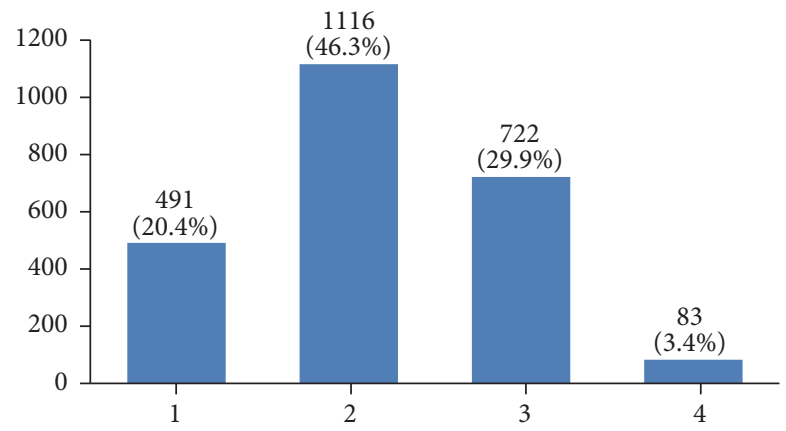

- Tumor stage

Figure 20: The tumor stage of the studied breast cancer cases.

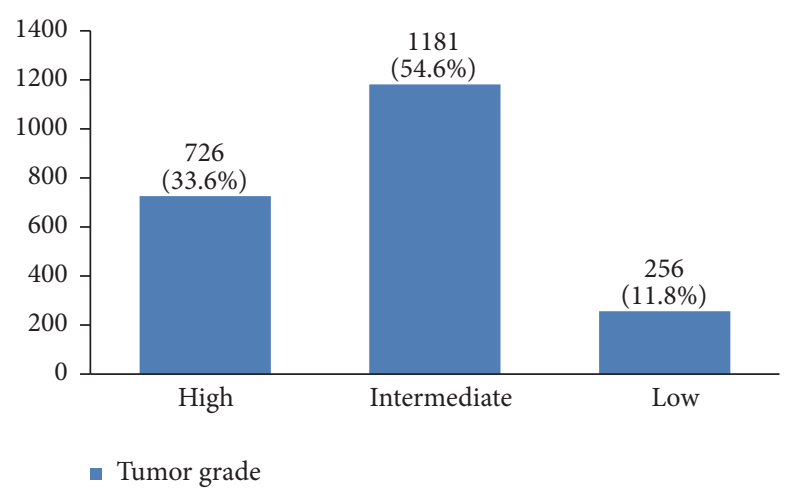

FIgURE 21: The tumor grade of the studied breast cancer cases.

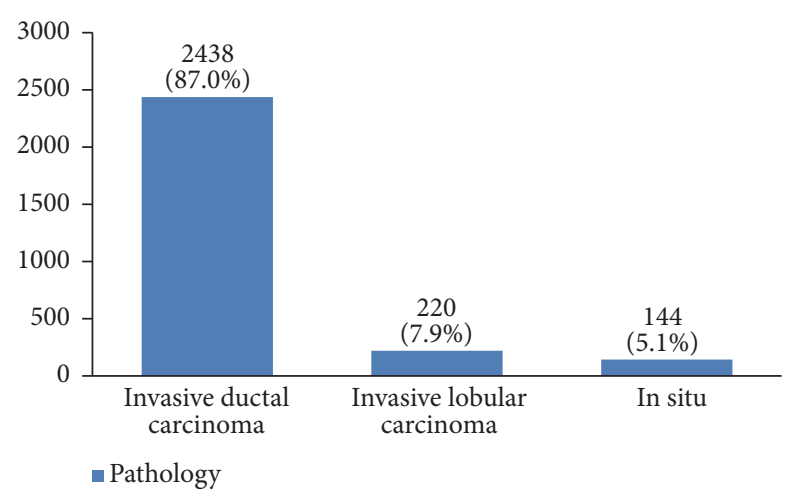

FIGURE 22: The pathology of the studied breast cancer cases.

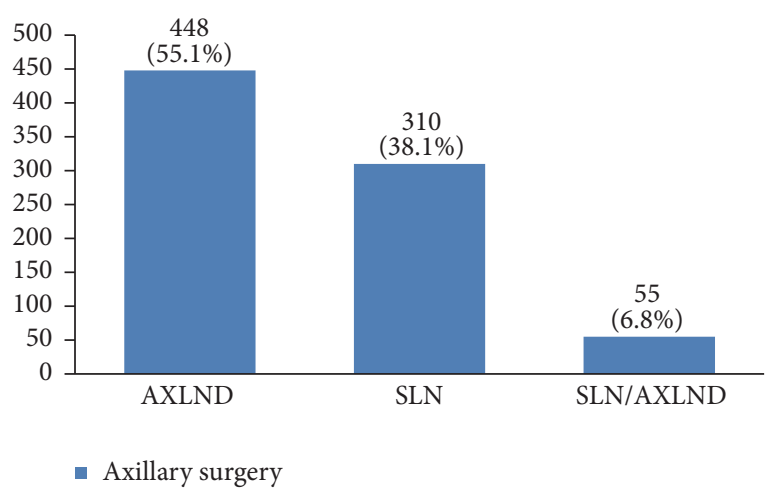

FIgURE 23: The axillary surgery type of the studied breast cancer cases.

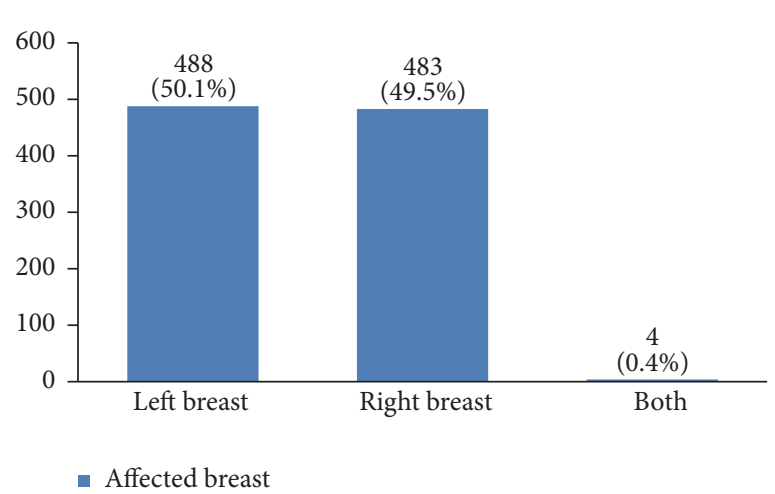

FIGURE 24: The involved breast sides (left or right) in the studied cases.

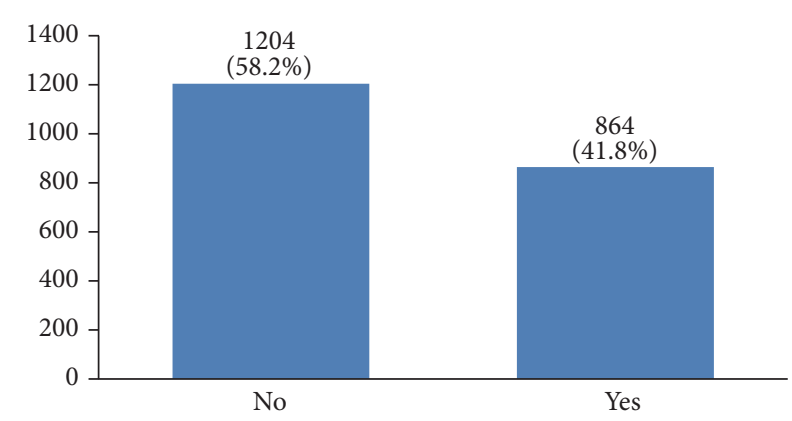

- Lymphovascular invasion

FIGURE 25: The percentage of lymphovascular invasion in the studied cases.

In most patients both sides of their bodies (right and left breasts) were involved equally and there were just a few cases with cancer on both sides (Figure 24). $42 \%$ of the patients had lymphatic vascular invasion (Figure 25). Positive estrogen receptor $(\mathrm{ER}+)$ was reported in $70 \%$ of cases compared to $66 \%$ who had positive progesterone receptor $(\mathrm{PR}+$ ) (Figures 26 and 27).

Furthermore, $28 \%$ of cases were human epidermal growth factor receptor 2 (HER2) negative, $14 \%$ had HER2 +1, 23\% had HER2 +2, and 35\% had HER2 +3 (Figure 28). P53 


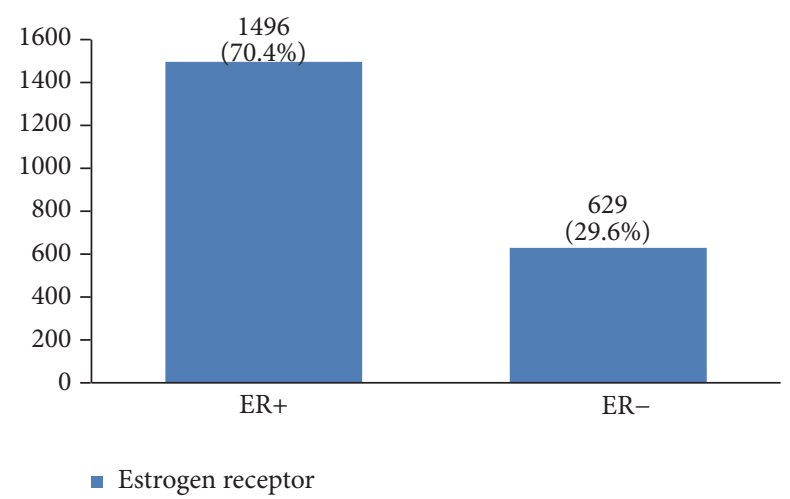

FIGURE 26: The percentage of estrogen receptor in the studied cases.

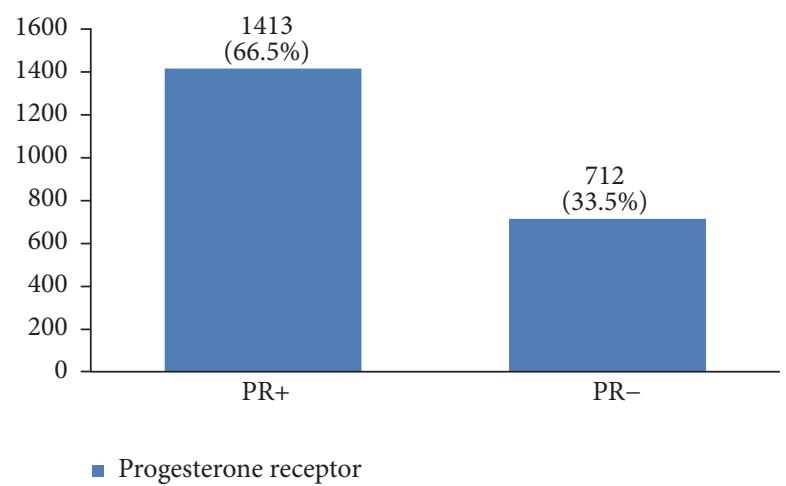

FIGURE 27: The percentage of progesterone receptor in the studied cases.

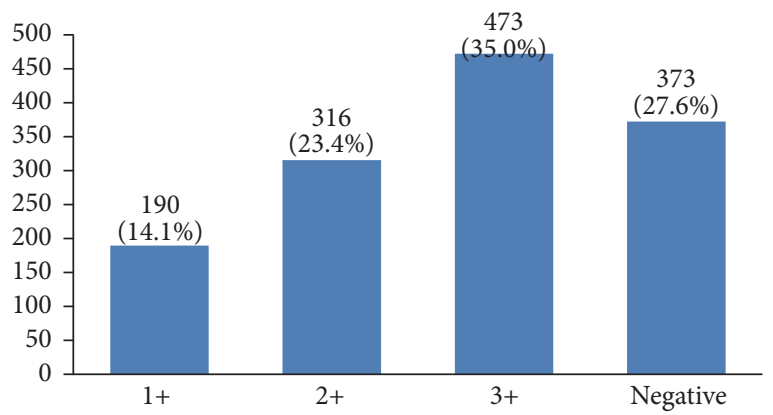

- Human epidermal growth factor receptor 2 (HER2)

FIGURE 28: The distribution of HER2 types in the studied cases.

was positive in $38 \%$ of the cases (Figure 29). $89 \%$ of the studied women had undergone adjuvant chemotherapy, $9 \%$ had undergone neoadjuvant chemotherapy, and $2 \%$ did not receive any chemotherapy (Figure 30). Most patients (95\%) had received external radiotherapy after surgery and a limited number of cases $(5 \%)$ had received intraoperative radiotherapy (Figure 31). 90\% of the patients had only received Tamoxifen for hormone therapy regimen (Figure 32).

Recurrence happened in $11 \%$ of the studied women. Most of them (69\%) had happened in the first five years of diagnosis

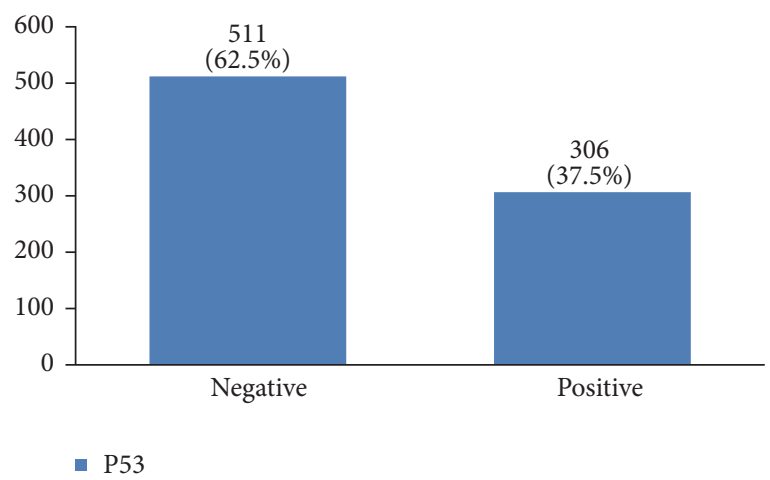

Figure 29: The distribution of P53 in the studied cases.

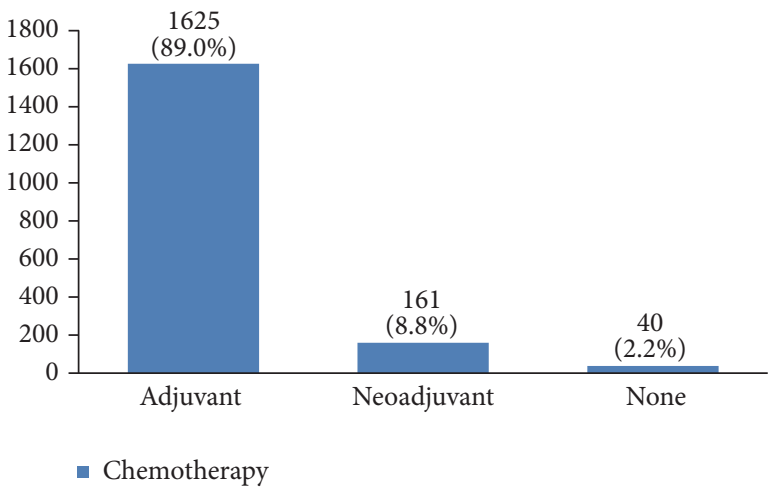

FIgURE 30: The chemotherapy type in the studied cases.

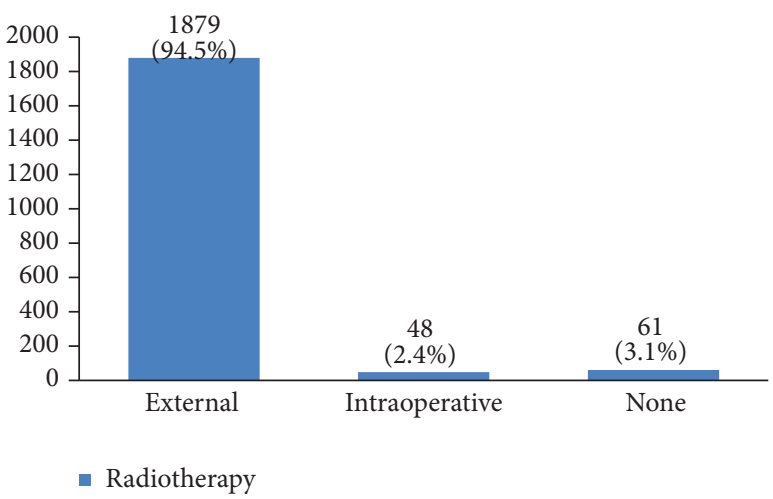

FIGURE 31: The radiotherapy type in the studied cases.

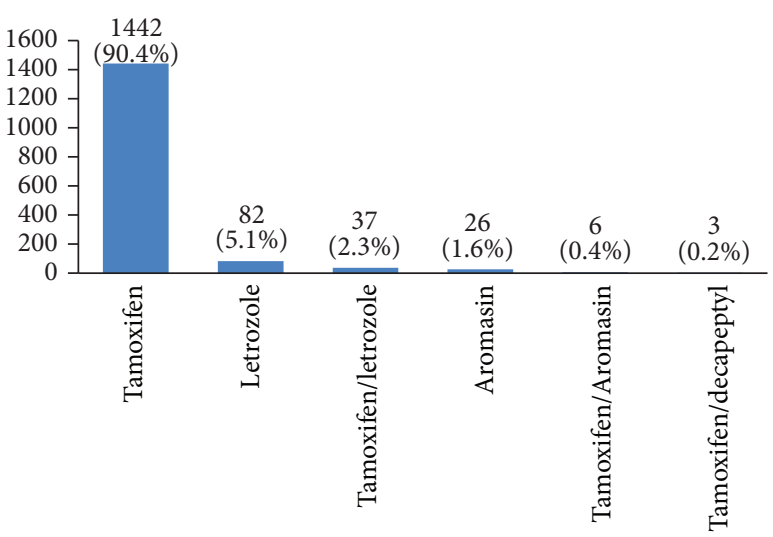

- Hormone type

FIGURE 32: The hormone type of the studied cases. 


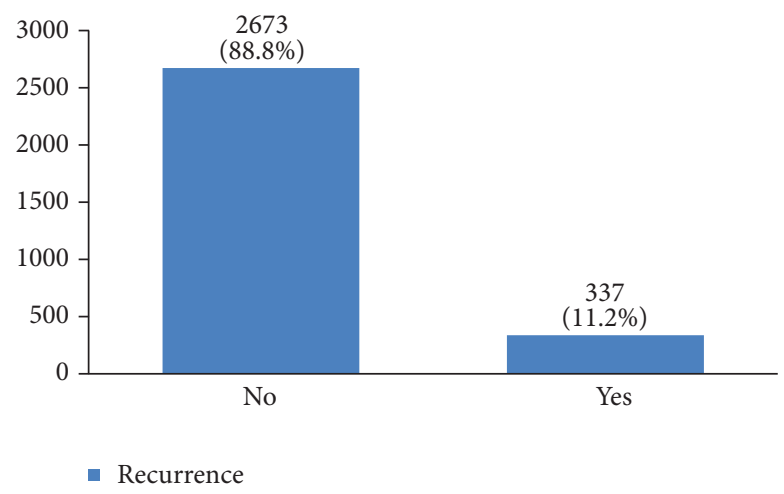

FIGURE 33: The percentage of recurrence in the studied cases.

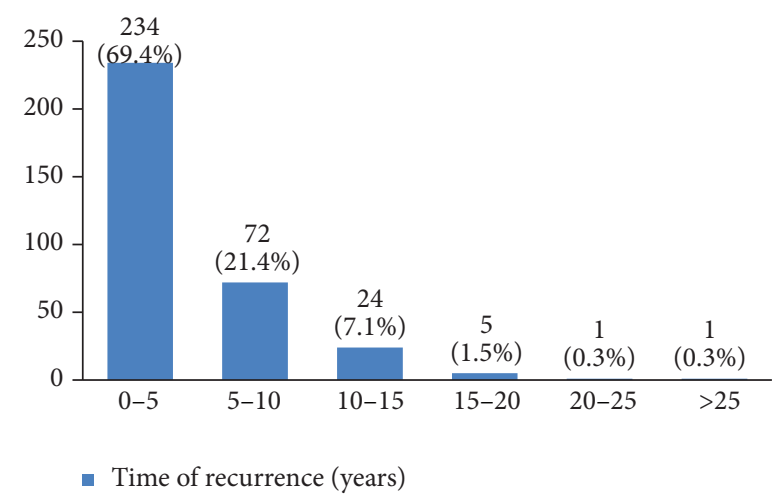

FIgURE 34: The time of recurrence in the studied cases.

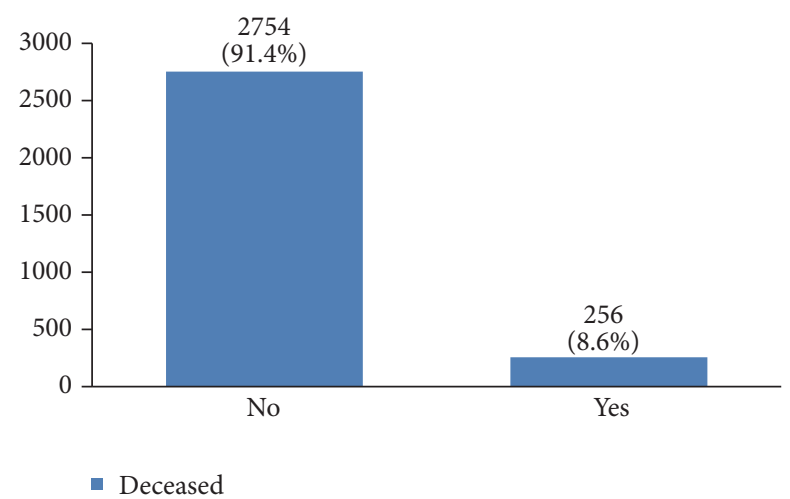

FIGURE 35: The percentage of the deceased because of breast cancer in the studied cases.

(Figures 33 and 34). 8.6\% of the patients had died mostly in the first five years after diagnosis (Figures 35 and 36).

\section{Discussion}

The risk of getting breast cancer increases with age and most breast cancers occur in women older than 50 years old $[6,7]$. In our study, most women with breast cancer were 40 to 50 years old. This is in accordance with other similar studies, which have stated that breast cancer occurs a decade earlier in Iranian women compared to women of western countries [4, 8-10]. Today, since $46 \%$ of Iran's population is 20 to 44

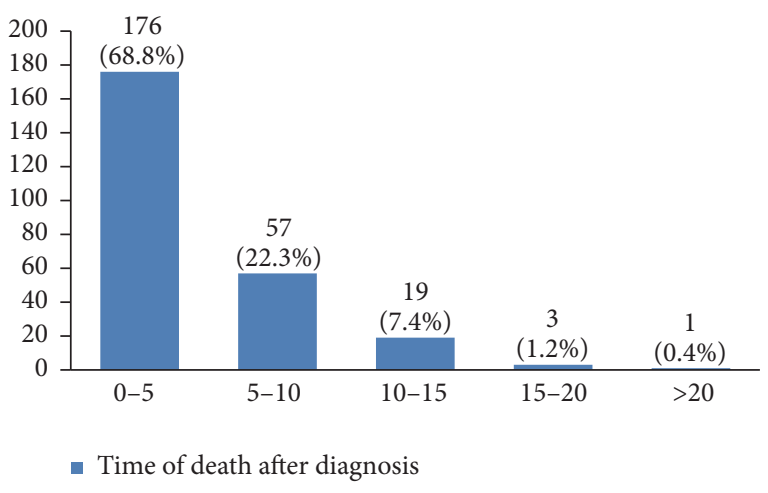

FIGURE 36: The time of death after breast cancer diagnosis in the studied cases.

years old (around 19 million women) [11], finding the best screening method for such a big population is the next step for early diagnosis of this disease and improving Iranian women's life quality.

Some studies have found an association between educational status and breast cancer [12]. Our findings show that most Iranian women with breast cancer are educated. Since having medical literacy is an indicator of social status, it is important to investigate the relationship between education and breast cancer in more detail.

Around $94 \%$ of our patients were married and according to some studies, being married can have a positive effect on the early diagnosis, treatment, and survival of breast cancer $[13,14]$. According to Iran's national statistics, around $70 \%$ of Iranian women aged 15 to 65 years old are married.

Around $41 \%$ of the studied women had up to two pregnancies and $50 \%$ had up to two childbirths. In this regard, it has been shown that multiparity has a preventive effect against breast cancer [3] and nulliparity increases the risk of breast cancer [15-19].

In our study, $30 \%$ of the studied women had experienced an abortion, but there is still controversy about the relationship between abortion and breast cancer [20-25]. Also, many studies have found that breastfeeding can decrease the risk of breast cancer occurrence [26-30]. Breastfeeding for less than 24 months is a risk factor of breast cancer [31]. Although there are many recommendations for breastfeeding for at least 24 months in Iran, 12\% of the studied women had not breastfed their children. To find out whether the duration of breastfeeding on the whole or for each successful labor is influential on the risk of breast cancer requires further investigation.

Having a positive family history of breast cancer is a risk factor for breast cancer. Familial breast cancer consists of $20-30 \%$ of all breast cancer cases $[3,6,7,32]$. In our study, $18 \%$ of patients had first- or second-degree family member(s) with breast cancer.

Hormone replacement therapy increases the risk of breast cancer occurrence [3, 31-35]. 29\% of our patients had a history of hormone consumption. More studies are needed for a better understanding of the association between hormone replacement therapy and breast cancer in Iranian women. 
Increasing fat intake can also increase the risk of breast cancer occurrence $[36,37]$. In this regard, $48 \%$ of our patients had a high-fat diet. A high-fat diet can result in obesity and increasing the body mass index leads to higher risks of this cancer [38-40].

Smoking can increase the risk of breast cancer occurrence $[36,41]$. Unfortunately, the number of women smokers is increasing. According to the Iranian Atlas of Women, 4.3\% of Iranian women were smokers in 2004. This has increased to $6.9 \%$ in 2010 [11]. In our study, $6.6 \%$ of the studied women were smokers. This shows that the percentage of women with breast cancer who are smokers is the same as the general population. Because this study has covered a period from 1998 to $2014,6.6 \%$ smoking rate in Iranian women for the whole period may indicate a higher prevalence of smoking in breast cancer patients.

According to the national assessment of health and diseases, the prevalence of diabetes in cities, villages, and the whole country is $2.9 \%, 1.2 \%$, and $2.3 \%$, respectively. The high percentage of women with breast cancer who also had diabetes $(34 \%)$ compared to the general population shows that there might be an association between diabetes and breast cancer and that diabetes might also influence the treatment outcomes of this cancer [42-46].

About $66 \%$ of our patients had experienced a natural menopause, while one-third had a history of hysterectomy. It has been shown that there is an association between late menopause and an increased risk of breast cancer [6].

Breast conserving treatment can be done in all stages of breast cancer, unless the breast size does not allow it. $59 \%$ of our patients underwent breast conserving treatment. However, this method can be used more often because it has a survival rate similar to modified radical mastectomy and the recurrence rate has also been similar in all types of breast conserving treatments [47-49]. Our data can be a valuable resource to evaluate local and distant recurrences and survival rate of various breast conserving treatments in Iranian patients.

In our study, $55 \%$ of the patients were diagnosed with a $2 \mathrm{~cm}$ to $5 \mathrm{~cm}$ tumor. Because tumor size is an important factor in staging breast cancer, type of treatment, and survival rate [50], developing a national program for increasing women's awareness about the benefits of screening is necessary. More than 10 lymph nodes had been removed in $44 \%$ of studied women but only $53 \%$ had one or more positive lymph nodes.

Almost half of the tumors had been detected in stage 2 . Tumor stage is also an important factor in local and distant recurrences, survival rate, and having an effective early diagnosis program. The regional distribution of stages 3 and 4 of the tumor in Iran should be explored in future studies. More than $50 \%$ of tumors were with intermittent grade. Since tumor grading is influential in the treatment outcome [51], further studies should be done with multivariate analysis to determine the effective factors on tumor grading.

Most tumors (87\%) were invasive ductal carcinoma which is in agreement with other studies [11, 52, 53]. Because pathology type is related to recurrence and disease-free survival [54], we are very interested to do further studies to find out which factors have a significant association with the type of pathology.

About 55\% of our patients had undergone axillary surgery. Because the type of axillary surgery usually depends on breast cancer stage, it shows that most breast cancer patients in our study were diagnosed beyond stage 1. Thus, more screenings are needed for early detection of this disease. Although in some studies the left breast had been more involved, in our study both breasts were involved equally.

Lymphovascular invasion is a predicting factor of tumor metastasis and an important prognostic factor in patients with lymph node-negative and invasive breast cancer [6]. In our study, lymphovascular invasion was found in $42 \%$ of the cases. The next step is to investigate interactions between lymphovascular invasion and other factors to predict treatment outcome and recurrence.

Hormone receptor status is a main factor in planning breast cancer treatment. In our study, $70 \%$ of breast cancers were positive for estrogen receptor and $67 \%$ were positive for progesterone receptor. Breast cancers with HER2 gene amplification or HER2 protein overexpression are called HER2-positive. HER2-positive breast cancers tend to grow more quickly and are more likely to spread and come back compared to HER2-negative breast cancers. HER2 is also a predictive and prognostic factor for breast cancer [6]. Previous studies in Iran have reported a $14 \%$ to $71 \%$ prevalence of this factor in breast cancer patients, which might be due to the difference in their measurement methods. In this study, HER $2+3$ was $35 \%$, which is much more than other countries $(10 \%-15 \%)[3,15,17,29]$. The importance of this factor is that breast cancer patients with HER2 should have their own special treatment, such as Herceptin treatment for HER2 +3. Clinical studies have shown that overexpression of HER2 is associated with a poorly differentiated tumor, high proliferation ability, positive lymph node, less hormone receptor expression [6], and a higher risk of recurrence. To determine whether this was the case with our patients requires further multivariate studies.

About $37.5 \%$ of our patients were P53 positive. Several factors, such as estrogen and progesterone receptors, human epidermal growth factor receptor 2 (HER2), age, stage, grade, time since metastatic development, and the site of metastasis, have been well identified as predictive criteria for this cancer's prognosis. P53 is also a well-studied marker in breast cancer, but its significance in predicting clinical outcome remains controversial [32].

Most of our patients (89\%) received adjuvant therapy. Neoadjuvant therapy was prescribed for only $9 \%$ of the cases. Chemotherapy analysis of early breast cancer showed that this treatment can decrease chances of recurrence and mortality in women younger than 70 years old who have breast cancer at stages $1,2 \mathrm{~A}$, and $2 \mathrm{~B}[6]$. Neoadjuvant therapy provides the opportunity to study primary tumor response and metastases to regional lymph nodes to characterize a special regimen.

Radiotherapy is done at all stages of breast cancer whether the patient has undergone breast conserving surgery or modified radical mastectomy. In recent years, intraoperative radiotherapy is done alongside breast conserving surgery. $94.5 \%$ of our patients received external radiotherapy and $3 \%$ 
were candidates for intraoperative radiotherapy in the last two years. According to some studies, Herceptin decreases mortality up to $33 \%$ and recurrence up to $50 \%$ compared to cases that have only received chemotherapy [6]. Only $7 \%$ of our studied women had received Herceptin.

The recurrence rate in our study was $11 \%$, with $69 \%$ occurring within the first five years after treatment. Breast cancer is the fourth cause of death due to cancer in the world, but it is still a common cause of death due to cancer among women in developing countries. In our study, $8 \%$ of the women died due to breast cancer. The burden of this disease is expected to increase in developing countries $[55,56]$. The mean five-year survival rate of Iranian women with breast cancer was $71 \%$ in 2007 [5] compared to $92 \%$ in the US [6]. This figure was $69 \%$ in our 16 -year period retrospective study.

\section{Conclusion}

Our study revealed original findings that can be used in national policymaking to find the best screening method for early detection and to improve the quality of care and prevention of breast cancer in Iran. It also provided a rich data source for bivariate and multivariate analysis (modeling). We are using this data to develop a balanced score card for recurrence and overall survival for newly diagnosed patients.

\section{Conflicts of Interest}

The authors declare that they have no conflicts of interest.

\section{Acknowledgments}

The authors would like to thank Seyed Muhammed Hussein Mousavinasab for his sincere cooperation in editing this text.

\section{References}

[1] H. A. Wahba and H. A. El-Hadaad, "Current approaches in treatment of triple-negative breast cancer," Cancer Biology and Medicine, vol. 12, no. 2, pp. 106-116, 2015.

[2] World Cancer Research Fund International, "Breast Cancer Statistics," 2016, http://www.wcrf.org/int/cancer-facts-figures/ data-specific-cancers/breast-cancer-statistics.

[3] M. E. Akbari and G. Mohammadi, Womens Cancers of Iran, Mohsen Publications, Tehran, 2014, (Farsi).

[4] CDC Cancer Office, "National Cancer Registry Report 2007-8," Tech. Rep., Tehran: Ministry of Health, Treatment and Education of Iran, Iran, 2009.

[5] S. M. Mousavi, A. Montazeri, M. A. Mohagheghi et al., "Breast cancer in Iran: an epidemiological review," The Breast Journal, vol. 13, no. 4, pp. 383-391, 2007.

[6] K. K. Hunt, J. F. R. Robertson, and K. I. Bland, The Breast. in. Schwartz Principles of Surgery, vol. 1, McGraw-Hill, New York, 10th edition, 2015.

[7] Breast Cancer Organization, “US Breast Cancer Statistics," 2016, http://www.breastcancer.org/symptoms/understand_bc/statistics.

[8] D. Saslow, C. Boetes, W. Burke et al., "American Cancer Society Guidelines for Breast Screening with MRI as an Adjunct to
Mammography," CA: A Cancer Journal for Clinicians, vol. 57, no. 2, pp. 75-89, 2007.

[9] S. Haghighat, M. Akbari, S. Ghaffari, and P. Yavari, "Standardized Breast Cancer Mortality Rate Compared to the General Female Population of Iran," Asian Pacific Journal of Cancer Prevention, vol. 13, no. 11, pp. 5525-5528, 2012.

[10] A. Rezaianzadeh, S. Heydari, H. Hosseini, A. Haghdoost, E. Barooti, and B. L. Kamran, "Prevalence of Breast Cancer in a Defined Population in Iran," Iranian Red Crescent Medical Journal, vol. 13, no. 9, pp. 647-650, 2011.

[11] M. E. Akbari, H. Mirzaei, and H. Soori, "Five-year survival of breast cancer in Shohada-e-Tajrish and Jorjani hospitals," Hakim J, vol. 9, no. 2, pp. 39-44, 2006, (Farsi).

[12] M. Sepandi, M. Akrami, H. Tabatabaee et al., "Breast Cancer Risk Factors in Women Participating in a Breast Screening Program: a Study on 11,850 Iranian Females," Asian Pacific Journal of Cancer Prevention, vol. 15, no. 19, pp. 8499-8502, 2014.

[13] P. Documet, T. M. Bear, J. D. Flatt, L. Macia, J. Trauth, and E. M. Ricci, "The Association of Social Support and Education With Breast and Cervical Cancer Screening," Health Education \& Behavior, vol. 42, no. 1, pp. 55-64, 2015.

[14] A. A. Aizer, M. H. Chen, and E. P. McCarthy, "Marital status and survival in patients with cancer," Journal of the American Society of Clinical Oncology, vol. 31, no. 31, pp. 3869-3876, 2013.

[15] C. E. DeSantis, S. A. Fedewa, A. G. Sauer, J. L. Kramer, R. A. Smith, and A. Jemal, "Breast cancer statistics, 2015: convergence of incidence rates between black and white women," $C A$ : $A$ Cancer Journal for Clinicians, vol. 66, no. 1, pp. 31-42, 2016.

[16] E. Barooti, A. A. Haghdoost, and H. Hosseini, "Vulnerable household women's health assessment (VH-WHAT): Protocol design and implementation," Iran Red Crescent Med J, vol. 12, no. 4, pp. 358-364, 2010.

[17] S. J. Lord, L. Bernstein, K. A. Johnson et al., "Breast Cancer Risk and Hormone Receptor Status in Older Women by Parity, Age of First Birth, and Breastfeeding: A Case-Control Study," Cancer Epidemiology Biomarkers \& Prevention, vol. 17, no. 7, pp. 17231730, 2008.

[18] H. Ma, L. Bernstein, M. C. Pike, and G. Ursin, "Reproductive factors and breast cancer risk according to joint estrogen and progesterone receptor status: a meta-analysis of epidemiological studies," Breast Cancer Research, vol. 8, no. 4, article R43, 2006.

[19] K. Britt, A. Ashworth, and M. Smalley, "Pregnancy and the risk of breast cancer," Endocrine Related Cancer, vol. 14, no. 4, pp. 907-933, 2007.

[20] G. A. Colditz, H. J. Baer, R. M. Tamimi, and J. F. Fraumeni, "Breast cancer," in Cancer Epidemiology and Prevention, D. Schottenfeld and J. F. Fraumeni, Eds., Oxford University Press, New York, NY, USA, 3rd edition, 2006.

[21] J. Guo, Y. Huang, L. Yang et al., "Association between abortion and breast cancer: an updated systematic review and metaanalysis based on prospective studies," Cancer Causes \& Control, vol. 26, no. 6, pp. 811-819, 2015.

[22] S. M. Karim, W. Baeshen, S. N. Neamatullah, and B. Bin, "Oral Contraceptives, Abortion and Breast Cancer Risk: a Case Control Study in Saudi Arabia," Asian Pacific Journal of Cancer Prevention, vol. 16, no. 9, pp. 3957-3960, 2015.

[23] G. K. Reeves, S. W. Kan, T. Key, and et al., "Breast cancer risk in relation to abortion: results from the EPIC study," Int J Cancer, vol. 119, no. 7, pp. 1741-1745, 2006.

[24] "ACOG Committee Opinion No. 434: Induced Abortion and Breast Cancer Risk," Obstetrics \& Gynecology, vol. 113, no. 6, pp. 1417-1418, 2009. 
[25] K. D. Henderson, J. Sullivan-Halley, P. Reynolds et al., "Incomplete pregnancy is not associated with breast cancer risk: the California Teachers Study," Contraception, vol. 77, no. 6, pp. 391396, 2008.

[26] K. O. Hajian-Tilaki and T. Kaveh-Ahangar, "Reproductive factors associated with breast cancer risk in northern Iran," Medical Oncology, vol. 28, no. 2, pp. 441-446, 2011.

[27] D. M. Parkin, S. L. Whelan, J. Ferlay, and et al., Cancer Incidence in Five Continents, vol. 6, International Agency for Research on Cancer, Lyon, France, 1997.

[28] C. Nagata, T. Mizoue, K. Tanaka et al., "Breastfeeding and Breast Cancer Risk: An Evaluation Based on a Systematic Review of Epidemiologic Evidence Among the Japanese Population," Japanese Journal of Clinical Oncology, vol. 42, no. 2, pp. 124-130, 2012.

[29] Collaborative Group on Hormonal Factors in Breast Cancer, "Breast cancer and breastfeeding: collaborative reanalysis of individual data from 47 epidemiological studies in 30 countries, including 50302 women with breast cancer and 96973 women without the disease," The Lancet, vol. 360, no. 9328, pp. 187-195, 2002.

[30] M. Awatef, G. Olfa, H. Imed et al., "Breastfeeding reduces breast cancer risk: a case-control study in Tunisia," Cancer Causes \& Control, vol. 21, no. 3, pp. 393-397, 2010.

[31] J. A. Eden, "Breast cancer, stem cells and sex hormones. Part 2: The impact of the reproductive years and pregnancy," Maturitas, vol. 67 , no. 3, pp. 215-218, 2010.

[32] R. Largillier, J. M. Ferrero, J. Doyen, and et al., "Prognostic factors in 1,038 women with metastatic breast cancer," Ann Oncol, vol. 19, no. 12, pp. 2012-2019, 2008.

[33] L. J. Ricks, A. Ewing, N. Thompson, and et al., "Family history of cancer associated with breast tumor clinicopathological features," J Community Genet, vol. 5, no. 3, pp. 233-240, 2014.

[34] J. Bae and E. H. Kim, "Hormone Replacement Therapy and Risk of Breast Cancer in Korean Women: A Quantitative Systematic Review," Journal of Preventive Medicine and Public Health, vol. 48, no. 5, pp. 225-230, 2015.

[35] L. Predná, M. Habánová, E. Sláviková, and J. Wyka, "Hormonal contraceptives and hormone replacement therapy as a possible factor of breast cancer," Rocz Panstw Zakl Hig, vol. 66, no. 3, pp. 269-274, 2015.

[36] S. Friis, A. Kesminiene, C. Espina, A. Auvinen, K. Straif, and J. Schüz, "European Code against Cancer 4th Edition: Medical exposures, including hormone therapy, and cancer," Cancer Epidemiology, vol. 39, pp. S107-S119, 2015.

[37] M. H. Lotfi, S. Charkhatti, and S. Shobairi, "Breast cancer risk factors in an urban area of Yazd city-Iran, 2006," Acta Medica Iranica, vol. 46, no. 3, pp. 258-264, 2008.

[38] J. R. Palmer, E. Viscidi, M. A. Troester et al., "Parity, Lactation, and Breast Cancer Subtypes in African American Women: Results from the AMBER Consortium," Journal of the National Cancer Institute, vol. 106, no. 10, 2014.

[39] K. A. Brown and E. R. Simpson, "Obesity and breast cancer: progress to understanding the relationship," Cancer Research, vol. 70, no. 1, pp. 4-7, 2010.

[40] F. Z. Laamiri, A. Bouayad, A. Otmani, S. Ahid, M. Mrabet, and A. Barkat, "Dietery factor obesity microenvironnement and breast cancer," Gland Surgery, vol. 3, no. 3, pp. 165-173, 2014.

[41] F. McKenzie, P. Ferrari, H. Freisling et al., "Healthy lifestyle and risk of breast cancer among postmenopausal women in the European Prospective Investigation into Cancer and Nutrition cohort study," International Journal of Cancer, vol. 136, no. 11, pp. 2640-2648, 2015.

[42] A. Montazeri, J. Sadighi, F. Farzadi et al., "Weight, height, body mass index and risk of breast cancer in postmenopausal women: a case-control study," BMC Cancer, vol. 8, no. 1, p. 278, 2008.

[43] K. Hemminki, X. Li, J. Sundquist, and K. Sundquist, "Risk of Cancer Following Hospitalization for Type 2 Diabetes," The Oncologist, vol. 15, no. 6, pp. 548-555, 2010.

[44] A. Renehan, U. Smith, and M. S. Kirkman, "Linking diabetes and cancer: a consensus on complexity," The Lancet, vol. 375, no. 9733, pp. 2201-2202, 2010.

[45] M. Inoue, M. Iwasaki, T. Otani, S. Sasazuki, M. Noda, and S. Tsugane, "Diabetes mellitus and the risk of cancer: results from a large-scale population-based cohort study in Japan," Archives of Internal Medicine, vol. 166, no. 17, pp. 1871-1877, 2006.

[46] P. J. Goodwin, M. Ennis, K. I. Pritchard et al., "Fasting insulin and outcome in early-stage breast cancer: results of a prospective cohort study," Journal of Clinical Oncology, vol. 20, no. 1, pp. 42-51, 2002.

[47] C. la Vecchia, S. H. Giordano, G. N. Hortobagyi, and B. Chabner, "Overweight, obesity, diabetes, and risk of breast cancer: interlocking pieces of the puzzle," Oncologist, vol. 16, no. 6, pp. 726-729, 2011.

[48] M. Rezai, S. Kraemer, R. Kimmig, and P. Kern, "Breast conservative surgery and local recurrence," The Breast, vol. 24, pp. S100S107, 2015.

[49] M. V. Nijenhuis and E. J. Rutgers, "Conservative surgery for multifocal/multicentric breast cancer," The Breast, vol. 24, pp. S96-S99, 2015.

[50] E. R. Myers, P. Moorman, J. M. Gierisch, and et al., "Benefits and Harms of Breast Cancer Screening: A Systematic Review," JAMA, vol. 314, no. 15, pp. 1615-1634, 2015.

[51] M. E. Linnaus, A. C. Dueck, H. E. Kosiorek et al., "Regional recurrence in the era of sentinel lymph node biopsy," The American Journal of Surgery, vol. 210, no. 6, pp. 1155-1160, 2015.

[52] C. Jauffret, G. Houvenaeghel, and J. M. Classe, "Breast cancer prognostic factors: About 940 patients," Gynecol Obstet Fertil, vol. 43, no. 11, pp. 712-717, 2015 (French).

[53] M. Movahedi, S. Haghighat, M. Khayamzadeh, and et al., "Survival rate of breast cancer based on geographical variation in Iran, a national study," Iran Red Crescent Med J, vol. 14, no. 12, pp. 798-804, 2012.

[54] A. Montazeri, M. Vahdaninia, I. Harirchi et al., "Breast cancer in Iran: need for greater women awareness of warning signs and effective screening methods," Asia Pacific Family Medicine, vol. 7, no. 1, p. 6, 2008.

[55] C. Wu, S. Chen, H. Chang, Y. Lo, S. Hsueh, and Y. Lin, "Identification of patients with hormone receptor-positive breast cancer who need adjuvant tamoxifen therapy for more than 5 years," Journal of the Formosan Medical Association, vol. 115, no. 4, pp. 249-256, 2016.

[56] J. Ferlay, H. Shin, F. Bray, D. Forman, C. Mathers, and D. Parkin, GLOBOCAN 2008, Cancer Incidence and Mortality Worldwide: IARC CancerBase No. 10, International Agency for Research on Cancer, Lyon, France, 2010. 


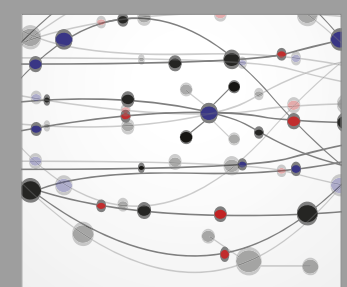

The Scientific World Journal
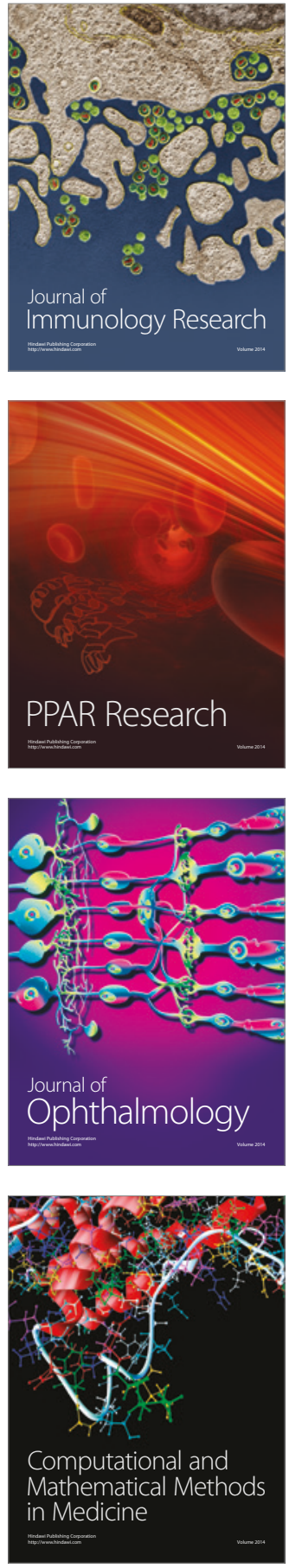

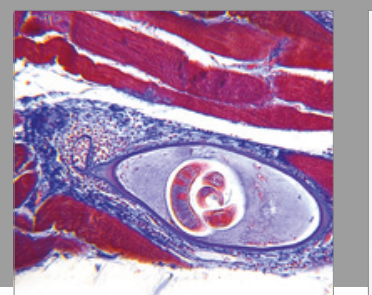

Gastroenterology Research and Practice
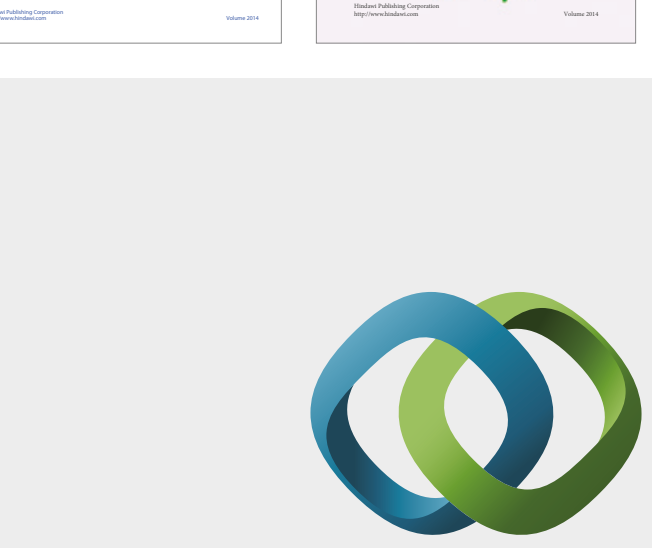

\section{Hindawi}

Submit your manuscripts at

https://www.hindawi.com
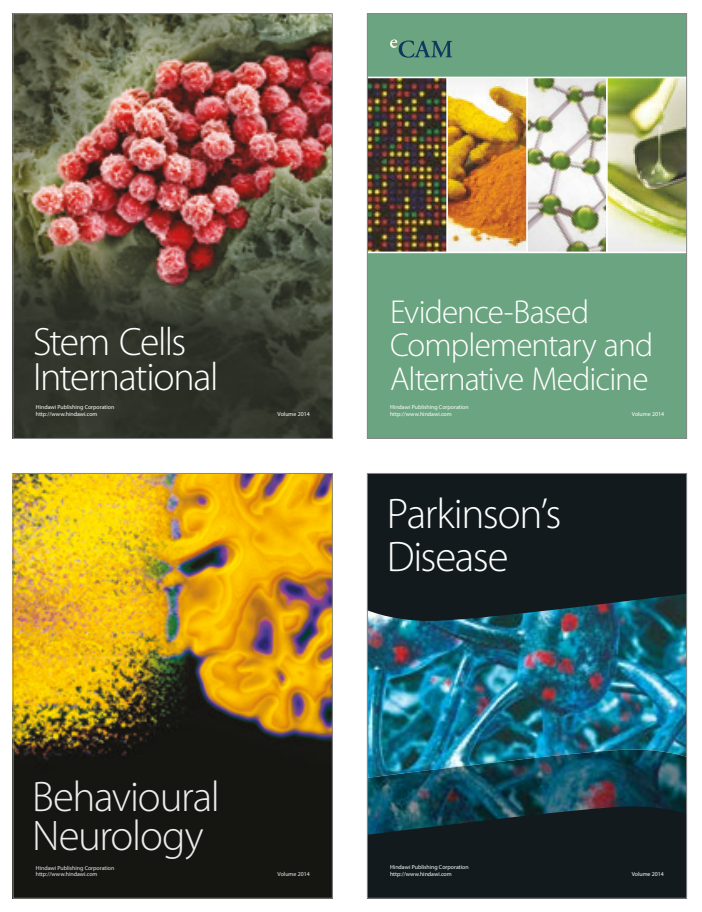
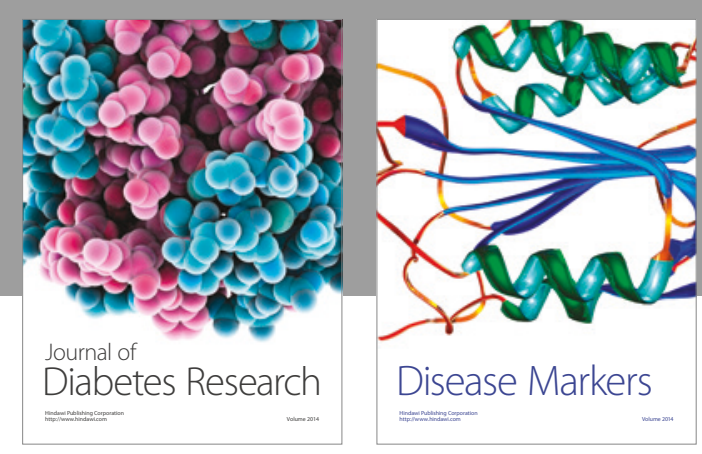

Disease Markers
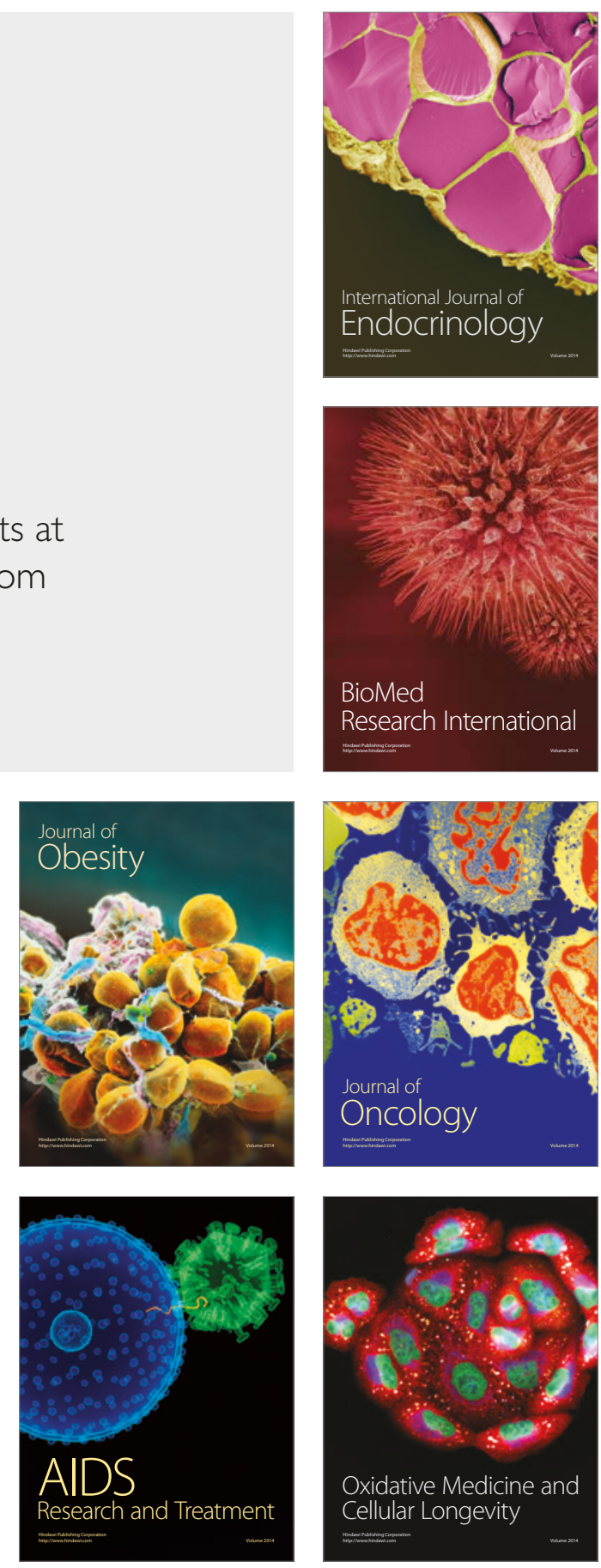